\title{
A desobediência civil é justa?
}

\section{Is civil disobedience fair?}

\author{
ÍSIS ESTEVES RUFFO ${ }^{1}$
}

Resumo: A pergunta que nos fazemos neste texto é se estamos justificados moralmente em desobedecer às leis em alguns casos, ou se é justo ou não o movimento de desobediência civil. A desobediência civil é um dos fenômenos marcantes do século XX caracterizada pela desobediência de cidadãos comuns às leis do Estado de forma deliberada. Por meio da não obediência às leis, civis podem demonstrar sua insatisfação ou indignação com o poder instituído. O fenômeno é especialmente interessante por não utilizar meios violentos contra instituições ou pessoas e nem tampouco resistência contra os meios de coação, mas ainda assim, ser eficiente. Os casos de sucesso nos movimentos civis podem ser explicados, em partes, por seu caráter pacifista, o que o permite angariar a simpatia da sociedade. Entretanto, a não-violência deve ser entendido especialmente como estratégia política, pois assume que o consentimento é o real fundamento do poder do Estado sobre as pessoas e que se esse for negado, forças coercitivas não terão legitimidade. A desobediência civil, portanto, pode ser considerada justa.

Palavras-chave: Desobediência civil. Justiça. Estado. Sociedade.

Abstract: The question we ask ourselves in this text is whether we are morally justified in disobeying the laws in some cases, or whether the civil disobedience movement is just or not. Civil disobedience is one of the remarkable phenomena of the 2oth century, characterized by the disobedience of ordinary citizens to the laws of the State in a deliberate way. Through non-compliance with the laws, civilians can demonstrate their dissatisfaction or indignation with the instituted power. The phenomenon is especially interesting because it does not use violent means against institutions or people, nor does it resist resistance against means of coercion, but it is nonetheless efficient. The successful cases in the civil movements can be explained, in part, by their pacifist character, which allows them to win the sympathy of society. However, non-violence must be understood especially as a political strategy, since it assumes that consent is the real foundation of the State's power over people and that if it is denied, coercive forces will have no legitimacy. Civil disobedience, therefore, can be considered fair.

Keywords: Civil disobedience. Justice. State. Society.

\section{Introdução}

Um dos fenômenos marcantes que é possível apontar no século XX é o surgimento de uma nova forma de poder: A desobediência civil. Essa se caracterizava como uma resistência de parte da população diante de alguma lei instituída pelo Estado. Neste movimento, as pessoas desobedecem conscientemente às leis que consideram injustas. Entretanto, não utilizam meios violentos. Obviamente, tal

\footnotetext{
${ }^{1}$ Bacharel e licenciada em filosofia pela Universidade Federal de São João del-Rey em 2016. Atualmente, mestranda em filosofia com ênfase em ética e metaética, pela Universidade Federal de Minas Gerais. E-mail: isis.ruffo@gmail.com
} 
atividade sofre algum tipo de repressão, muitas vezes, violenta, o que em tudo, fortalece a reivindicação angariando simpatia de pessoas externas ao movimento.

Entretanto, embora seja claro que a não-violência dos movimentos é algo interessante e que gera simpatia, o não uso da violência é mais do que algum tipo de compromisso ético em relação à humanidade. É, verdadeiramente, uma estratégia política. Diante do Estado, a força de resistência da população, se for física, pode ser facilmente suprimida. O Estado, normalmente, tem controle sobre os meios de coação: isso inclui armas e pessoas treinadas neste ofício, além de todas as instituições que preservam a lei. Em um confronto direto, a população descontente teria poucas chances de sucesso. A resistência não-violenta, por outro lado, não precisa deste confronto direto, pois utiliza a ferramenta de violência do Estado contra ele próprio.

A desobediência civil, como forma de manifestação, é um fenômeno de grande interesse ainda hoje, pois envolve um mecanismo complexo de poder que pode indicar uma das principais bases das sociedades: $O$ fenômeno civil parece ressaltar que a verdadeira força do Estado reside mais no consentimento que as pessoas dão em ser governadas do que nos meios de coação disponíveis. Muitos movimentos de desobediência levaram a transformações significativas, o que parece comprovar este ponto.

Entretanto, por ser uma forma de poder paralela ao Estado, podemos nos perguntar se ela é justa, embora contrária a lei. Neste texto, procuraremos refletir um pouco sobre esse aspecto, trazendo o pensamento de Immanuel Kant e Hannah Arendt. Após a investigação, assumiremos que é possível compreender a desobediência civil como movimento, não só eficiente, mas também justo, pois está de acordo com o direito e a moral, conforme é possível deduzir pela máxima kantiana explorada no final deste texto: “Todas as máximas que necessitam da publicidade (para não fracassarem no seu fim) concordam simultaneamente com o direito e a política." (KANT, 2008 [1975] [itálico original], p. 184). Também é uma mobilização eficiente, conforme demonstra a própria história dos movimentos, na qual é possível apontar importantes conquistas para os direitos civis.

\section{A Desobediência Civil}

Durante o século XX, a Índia esteve sob o domínio da Grã-Bretanha. As leis que governavam aquele país viam de outro Estado e seu propósito não era a existência da sociedade indiana e, sim, sua exploração na forma de uma colônia. Uma dessas leis consistia na proibição da produção e extração do sal em todo país, excetuando as empresas inglesas.

Além da proibição da produção, o sal vendido era taxado com muitos impostos o que fazia o produto excessivamente caro. Então, no dia 12 de março de 1930, 
Mahatma Gandhi saiu de sua cidade, acompanhado de 77 seguidores, e marchou a pé por mais de 400 quilômetros ao longo de 25 dias até o litoral. Seu objetivo era desafiar a autoridade do governo inglês e desobedecer à lei do monopólio do sal.

Ao longo de sua marcha, milhares de novos seguidores se alinharam a Gandhi. Muitos funcionários públicos deixaram seus empregos e uma onda de indignação contra o domínio da Grã-Bretanha ganhou força entre os indianos. No dia 6 de abril, Gandhi chegou à praia e extraiu do mar da Índia um punhado de sal para si. Aquele foi um gesto simbólico que dizia claramente que os indianos não mais se submeteriam àquela lei, pois era injusta e inaceitável.

Este episódio ficou conhecido como a Marcha do Sal. Logo em seguida, uma série de outros protestos desenvolveram-se na Índia. Estas manifestações tinham a mesma natureza: desobedecer pacificamente às leis consideradas injustas pelos indianos e, assim, negar a autoridade do Estado inglês na Índia. Como resultado, vários indianos foram presos, inclusive o próprio Gandhi. Entretanto, algo novo estava acontecendo: aquelas pessoas desejavam ser presas. Havia, na prisão, um sentimento de orgulho e não de vergonha, pois tinham a confiança de que a punição era a verdadeira injustiça cometida.

Outros casos, em parte semelhantes em parte diferentes aconteciam nos Estados Unidos da América. Passados mais de cem anos após a Guerra civil americana, o Estado continuava a permitir e instituir leis segregacionistas que limitavam os direitos civis de uma grande parte da população em razão da cor de sua pele. Ao longo das décadas de 50 e 6o, vários movimentos negros reivindicaram uma sociedade com igualdade racial.

A separação entre negros e brancos era praticada em várias regiões, delimitando escolas e estabelecimentos específicos para brancos, ou específicos para negros. Uma série de outros costumes humilhantes, como a separação nos transportes públicos, eram praticados livremente. Além disso, os negros enfrentavam uma série de obstáculos para conseguirem exercer seus direitos de voto.

Neste período, vários grupos de negros se organizaram em protestos pacíficos. $\mathrm{Na}$ cidade de Neshville, um pequeno grupo de estudantes negros liderados por James Lawson, passaram a enfrentar às leis segregacionistas dos estabelecimentos comerciais. O grupo agia pacificamente, mas muitas vezes foi reprimido com violência e vários de seus membros foram presos. A causa ganhou adesão de milhares de outras pessoas que passaram a organizar passeios, panfletagens e financiar os custos legais com advogados e fianças decorrentes das prisões dos manifestantes. Devido às manifestações, os comerciantes locais começaram a ser prejudicados pela dificuldade de vender seus produtos. 
A repressão se tornou ainda mais violenta culminando em um ataque à bomba na casa de Alexander Looby, um importante advogado defensor dos manifestantes. Entretanto, após este atentado, os manifestantes de Neshville conseguiram realizar uma reunião com o prefeito da cidade o que foi o primeiro passo para uma mudança nas questões raciais locais. Este movimento culminou na dessegregação de instituições públicas e do comércio local.

Os diversos movimentos por direitos nos Estados Unidos culminaram no Ato dos Direitos Civis de 1964, que proibia a discriminação em locais públicos, nas contratações e nos programas dos governos, além de acabar com restrições que impediam uma parte da população negra de votar. Embora algumas ramificações dos movimentos negros utilizassem meios violentos, eles escapam ao objetivo deste texto, portanto não falaremos sobre eles. O nosso objetivo é destacar movimentos como de Neshville que não envolviam violência e que ganhavam a simpatia de várias pessoas devido ao seu caráter pacifista e também devido à justiça que inegavelmente reivindicavam.

Assim como na Índia, os movimentos negros apresentavam uma organização pacifista e civil. Contudo, há uma diferença importante de ser destacada: Os movimentos civis dos negros americanos se organizavam contra as leis instituídas por seu próprio país e não por um governo estrangeiro, como no caso da Índia. Os direitos civis para os negros já haviam sido conquistados, mas por uma série de costumes e leis subjacentes, eram negligenciados ou impedidos. Assim, as manifestações antissegregacionistas nos EUA, não eram idênticas àquelas que aconteciam na Índia, mas possuíam diversos pontos em comum.

Esta nova forma de poder ficou conhecida por desobediência civil, termo cunhado no século XX que caracterizou uma forma inédita de resistência. Henry David Thoreau é o autor célebre dessa temática e constantemente invocado nos debates sobre o tema. Sua justificação para a desobediência civil repousa sobre a relação entre a moralidade individual e as leis do Estado. A questão, como proposta por Thoreau, pode ser enunciada da seguinte maneira: Embora o mal de desobedecer à lei possa ser pior do que aquele causado por ela há, um único caso, em que é aceito que um cidadão desobedeça à lei: quando esta obriga que o próprio cidadão seja o agente da injustiça (THOREAU, 2012 [1849], p. 19).

Thoreau alega que não é obrigação de nenhum homem tornar o mundo um lugar melhor, mas é seu dever não cometer nenhuma injustiça. Assim, diante das injustiças cometidas pelo Estado, sejam elas inerentes ou não ao próprio funcionamento do sistema, o cidadão não possui nenhuma obrigação moral. Contudo, não pode sacrificar sua própria consciência, quando esta entra em conflito com o Estado (idem, p.18). Uma pessoa não está autorizada a cometer injustiça, mesmo que esta seja uma obrigação civil. Entretanto, ao contrário do que se pode ser levado a admitir inicialmente pelos exemplos dados, a desobediência civil não 
deve ser encarada como Thoreau a coloca. Os casos históricos citados e que produziram alguma mudança tinham em comum o fato de que não eram ações isoladas e individuais que brotavam simplesmente da consciência de um contestador. Eram fenômenos que contavam com a participação de um grupo de pessoas.

Hannah Arendt faz notar essa distinção em seu ensaio Desobediência Civil. Neste ensaio, ela aponta que o objetor de consciência, ou seja, aquele que por princípios morais ou religiosos se recusa a obedecer alguma lei, é diferente do contestador civil (ARENDT, 2008 [1969], p. 59). A individualidade da consciência restringe seu acesso às áreas de interesse do eu. O propósito é manter o indivíduo livre de ações que causem nele o sentimento de culpa. Porém, este princípio, por seu caráter subjetivo, jamais poderia ser universalizado, uma vez que ações com que algum homem pode ser incapaz de sobreviver, podem ser totalmente inócuas a outro (idem, p. 61). Além disso, a consciência não pode ser assumida como um guia seguro para a ação neste caso, pois ainda que as pessoas possuíssem uma grande capacidade de discernir o certo do errado, não é possível assumir que fariam uso dessa capacidade (idem, p. 61).

Encarada como ação individual, a desobediência civil raramente produz algum efeito. O objetor de consciência, no qual é possível classificar Thoreau, é, comumente, tratado pelo Estado como alguém excêntrico e de pouca ameaça (idem, p. 55-56) "mais interessante de observar do que de suprimir" (idem, p. 55). A desobediência civil, por outro lado, é um fenômeno de grupo.

A desobediência civil se caracteriza por ser uma organização de uma minoria em torno de uma opinião comum. Essa opinião sustenta que se deve desobedecer às políticas adotadas, mesmo que sejam apoiadas pela maioria (idem, p. 55). Ainda que essa opinião tenha brotado de uma mente individual, a adesão do grupo dá a ela uma validade especial, tornando-se uma opinião pública que pode conquistar novos adeptos. "No mercado, o destino da consciência não é muito diferente do destino da verdade do filósofo: torna-se uma opinião não diferenciável de outras opiniões. A força da opinião não depende da consciência, mas do número de pessoas com quem está associada" (idem, p. 64).

A desobediência civil se caracteriza, então, como um movimento político, no qual não apenas interesses individuais são considerados. Essa forma de poder pretende, portanto, alterar situações que atentam contra a constitucionalidade por meio de atos não violentos, porém ilegais. Diante disso, é possível se perguntar se em alguma circunstância é aceitável desobedecer às leis. Afinal, a desobediência civil é um meio justo de reivindicação e promoção de mudanças? Algumas objeções 
kantianas podem ser apresentadas contra a desobediência civil2 ${ }^{2}$ Este trabalho enfoca em especificamente duas delas: ações contrárias à publicidade e ausência de juízes adequados. Estas poderiam tornar a desobediência um meio injusto de reivindicar mudanças no Estado.

\section{Ações contrárias à publicidade}

A primeira objeção a ser considerada é encontrada no texto A Paz Perpétua e é também lembrada por Arendt no ensaio investigado nesse texto. Segundo Kant, "São injustas todas as ações que se referem ao direito de outros homens cujas máximas não se harmonizem com a publicidade.” (KANT, 2008 [1795] [itálico original], p. 178). Assim, se algo é justo, deve ser compatível com a divulgação de suas intenções.

Uma conspiração contra o Estado é injusta, pois se as intenções dos conspiradores se tornam públicas, o Estado toma as medidas para evitar que as ações se concretizem. Desse modo, toda conspiração deve ser feita às escondidas, sob o risco de não alcançar seu intento. As sociedades secretas e outras entidades que se organizam contra o Estado funcionam dessa maneira.

Entretanto, uma diferença fundamental pode ser apontada entre a conspiração e a desobediência civil, "a conspiração requer, não apenas 'aspirações conjuntas', mas sigilo, e a desobediência civil ocorre em público" (ARENDT, 2008 [1969], p. 88). Assim, não é o caso de identificarmos a desobediência civil com conspiração. Nos movimentos negros dos Estados Unidos, ou na resistência indiana, as intenções dos manifestantes eram públicas e conhecidas pelo Estado.

O intuito da desobediência é apontar a injustiça cometida pelo Estado por meio de alguma lei, portanto não faria sentido que as intenções não fossem amplamente difundidas. $\mathrm{O}$ que se pode pretender para que a desobediência produza algum fruto é que ela ganhe adeptos e se torne difícil para o Estado, ignorá-la. Deste modo, neste ponto, o contestador civil se distancia do revolucionário, pois este não pode expressar publicamente suas intenções.

O revolucionário também não reconhece a autoridade do Estado e pretende instaurar outro governo, enquanto que o contestador civil questiona a autoridade do Estado em relação a algumas leis, mas não em relação à legitimidade do uso da força de coação. Isso é demonstrado, como aponta Arendt, pelo não uso da violência característico da desobediência civil, contrastante com as estratégias revolucionárias (idem, p. 69-70). Apesar disso, revolucionário e contestador se aproximam quanto à finalidade de sua ação e neste ponto, ambos se distanciam do criminoso comum.

\footnotetext{
2 Essas críticas, extraídas do pensamento kantiano, não se referem à desobediência civil e sim ao direito dos cidadãos de revolução ou conspiração. As críticas apresentadas foram adaptadas para a desobediência civil.
} 
O criminoso comum desobedece às leis com o objetivo de trazer benefícios a si mesmo. Ao criminoso não interessa que outros ajam da mesma forma, portanto o que pretende não é de forma alguma uma mudança na lei.

O transgressor comum [...] age exclusivamente em seu próprio benefício; recusa-se a ser dominado pelo consentimento dos outros e só cederá ante a violência das entidades mantedoras da lei. Já o contestador civil, ainda que seja normalmente um dissidente da maioria, age em nome e para o bem de um grupo; ele desafia a lei e as autoridades estabelecidas no terreno da dissenção básica, e não porque, como indivíduo, queira algum privilégio para si (ARENDT, 2008 [1969], p. 69).

Assim, não é uma boa objeção à desobediência civil que seja injusta nestes termos [de suas intenções não poderem ser públicas]. Por esta razão, também não é o caso que seja possível identificar a desobediência civil com conspiração ou revolução, ainda que tenham pontos em comum. Por outro lado, não é possível reduzir nenhum desses movimentos a um crime comum.

\section{Quem seria o juiz em um conflito entre Estados e cidadãos?}

A segunda objeção que pode ser levantada contra a desobediência civil é encontrada no texto, Sobre a Expressão Corrente: Isto pode ser correto na teoria, mas nada vale na prática e pode ser resumida na seguinte questão: Em um conflito entre os cidadãos e o Estado, quem seria o juiz das ações de um e de outro? (KANT, 2008 [1793], p. 91).

Quando há um conflito entre cidadãos, o Estado é quem deve determinar a justiça em tal processo. Isso garantiria que os direitos individuais fossem preservados. Para isso, o Estado tem ampla autoridade sobre o julgamento das ações dos cidadãos, caso interfiram de alguma forma sobre a liberdade dos outros membros da comunidade. Cabendo ao Estado aplicar, se necessário, punições. Entretanto, em um conflito entre o Estado e o cidadão, como é o caso da desobediência civil, quem poderia ser o juiz de tal processo?

Nem o Estado nem os cidadãos poderiam agir como juízes neste processo, pois são as partes envolvidas na disputa. Seria necessário que existisse outro juiz. Este juiz não poderia ter uma autoridade menor que os envolvidos, pois assim sua decisão não seria respeitada e a justiça seria apenas a justiça do mais forte. Portanto, seria necessário um juiz que deveria ser superior aos dois - Estado e cidadão - que pudesse julgar tal conflito e aplicar as punições conforme a justiça. Contudo, segundo esse mesmo pensamento, seria necessário também outro juiz, superior ainda aos três, para julgar conflitos entre eles e isso se seguiria infinitamente (idem, p. 91-92).

Assim, em um movimento de desobediência civil, não há meios de determinar de que lado está a justiça por falta de um juiz adequado. Se, por outro lado, em uma 
análise histórica, parece que a justiça estava do lado dos contestadores, isso em nada acrescenta do ponto de vista formal, pois como destaca Kant, o lado vencedor parece sempre estar certo e seus líderes são glorificados como heróis, enquanto que, se os movimentos fracassam, são retratados como os piores inimigos (idem, p. 93).

Diante dessa crítica, não há meios de defender a desobediência civil, mas também não parece que de todo, ela a deslegitima. Pois uma pessoa pode desobedecer à lei. Por esta razão que na constituição de cada país estão expressas as punições proporcionais a cada infração. Se não todo o poder do Estado, ao menos uma parte dele, reside na capacidade de coagir a população para que aja em concordância com a lei e assim garantir a paz necessária para a sociedade ou outro fim qualquer. Entretanto, quando uma grande parte da população está disposta a desobedecer à lei, mesmo sabendo das punições e mesmo quando punido, permanece infringindo a lei, há algo de errado nesta situação. Ou esta população é extremamente corrompida em algum sentido moral, ou a constituição daquele Estado atenta contra algum princípio racional de uma forma que é quase impossível ignorar.

\section{Levando em consideração a questão anterior, a desobediência civil pode ser descartada como injusta?}

Nos movimentos de desobediência civil, temos o caso em que uma punição parece mais injusta que a violação à lei e isso pode ser uma razão para desobedecer a essa lei. Também, não é de todo ilegítimo ponderar que se uma lei colocar na prisão uma grande parcela da população e que esta não pareça nociva à sociedade, talvez seja o caso de repensá-la. Assim, temos que desobediência civil não pode alterar a constituição do Estado, mas pode tornar visível o ponto no qual ela falha em relação à própria racionalidade, sendo uma forma de poder paralela ao Estado, mas que não pode ser totalmente descartada como injusta.

Diante desta intuição, é possível se perguntar se, de alguma forma, é possível defender a desobediência civil, apesar de a segunda crítica apresentada ser de fato pertinente. Para isso, é relevante considerar alguns apontamentos que Arendt faz sobre o pensamento político kantiano no texto: "Lectures on Kant's Political Philosophy". Retornando à primeira crítica apresentada: "São injustas todas as ações que se referem ao direito de outros homens cujas máximas não se harmonizem com a publicidade." (KANT, 2008 [1795] [itálico original], p. 178) Arendt enfatiza que está máxima é apenas negativa, não sendo possível concluir a partir dela que as máximas que se harmonizarem com a publicidade são justas (ARENDT, 1992 [1982], p. 49). Afinal, governo e governados possuem regras diferentes, “[...] quem detém o supremo poder de decisão [governante] não precisa de ocultar suas máximas" (KANT, 2008 [1795], p. 183), mas isso, não necessariamente, faz delas justas. 
Kant aponta que a política e a moral não podem estar em conflito. Elas existem tendo a mesma teoria do direito por fundamento, diferindo apenas que uma é teorética [a moral], enquanto outra se refere ao direito aplicado [a política] (idem, p. 163). Assim, caso a política não esteja de acordo com o princípio moral, ela deveria ser reformulada, pois a aplicação deve se conformar à teoria e a política, por sua vez, deve se subordinar a moral (idem, p. 177).

As máximas da moralidade não apenas são compatíveis, mas necessitam da publicidade. Como destaca Arendt sobre o pensamento kantiano, "Publicidade é sempre o critério sobre corretude em sua moral [de Kant]" (ARENDT, 1992 [1982], p. 49). Deste modo, as máximas que necessitam de publicidade para alcançar o seu fim são morais e a política deve estar de acordo com a moralidade. Disto deriva outro princípio transcendental proposto por Kant: “Todas as máximas que necessitam da publicidade (para não fracassarem no seu fim) concordam simultaneamente com o direito e a política." (KANT, 2008 [1975] [itálico original], p. 184). Uma vez que a desobediência civil, conforme pensamento de Arendt, mas não de Thoreau, pode ser encaixada nesta categoria, não é absurdo supor que as reivindicações dos contestadores estão de acordo com os imperativos morais e que a política deve, portanto, atender a elas.

Diante disso, a segunda crítica apresentada: Em um conflito entre os cidadãos e o Estado, quem seria o juiz das ações de um ou outro? Permanece, de fato, pertinente, pois não haveria um juiz capaz de realizar tal julgamento. Contudo, em relação à desobediência civil, esta crítica apenas aponta que não seria possível determinar de qual lado está a justiça e não, exatamente, que esteja ao lado do Estado. Além disso, conforme o princípio transcendental proposto acima, a desobediência civil, conforme apresentada pelos exemplos neste texto, se harmoniza com a moralidade e consequentemente com a política e o direito. Assim, não é impossível assumir que a desobediência civil tenha sido um meio justo adotado por aquelas populações.

\section{Considerações finais}

A desobediência civil é um fenômeno inédito de resistência que pode ser apontado como um dos fatos marcantes do século XX. A contestação pacifica explora a base do poder do Estado sobre os cidadãos: o consentimento. Uma vez que as pessoas se recusem a cumprir às leis ou não reconheçam a autoridade do Estado em alguma situação, todo o seu poder de coação não parece totalmente eficiente.

Este texto assumiu que as duas críticas que podem ser levantadas facilmente contra a desobediência civil não são suficientes para torná-la injusta. Assumiu também que a desobediência civil, embora, por seu caráter civil, seja semelhante a muitos outros tipos de movimentos contra o poder do Estado, é um movimento totalmente novo característico do século passado: Não pode ser identificado com 
uma revolução ou conspiração, pois não pretende destruir o Estado vigente. Também não pode ser comparada com um crime comum, pois seus propósitos não são egoístas.

Por ser um movimento de reivindicação pautado na estratégia de nãoviolência, pode parecer a princípio que seu alcance seja pequeno. Contudo, ao longo da história, é possível apontar movimentos de desobediência civil que foram vitoriosos e não em pequenos conflitos, mas em situações de grande mudança social. Sobretudo, sobre a perspectiva do atual momento histórico, as conquistas da desobediência parecem simbolizar um avanço para os direitos civis.

Contudo, como todos os movimentos de força paralela ao Estado, sempre é possível perguntar sobre a sua justiça. Máximas como as sustentadas pela desobediência civil podem ser sustentadas sem que isso leve a um caos na sociedade? O mal provocado pelo descumprimento da lei, afinal, é sempre pior do que aquele provocado por uma lei injusta? Estas e muitas questões ainda podem ser levantadas que contrariem ou reforcem as conclusões deste texto.

\section{Referências}

ARENDT, H. Crises na República [Desobediência Civil]. Tradução: José Volkmann. 2ª̀ed. São Paulo: Perspectiva, 2008 [1969].

ARENDT, H. Lectures on Kant's Political Philosophy. Ronald Beiner (ed.), Chicago: The University of Chicago, 1992 [1982].

KANT, I. A Paz Perpétua e Outros Opúsculos: Sobre a expressão corrente: Isto pode ser correcto na teoria, mas nada vale na prática/ A Paz Perpétua. Tradução: Artur Morão. Lisboa: Edições 70, 2008 [1793] [1795].

THOREAU, H. D. A desobediência Civil. Tradução: José Geraldo Couto. São Paulo: Penguin Classics Companhia das Letras, 2012 [1849].

Submissão: 26. 09. 2019 / Aceite: 30. 03. 2020 